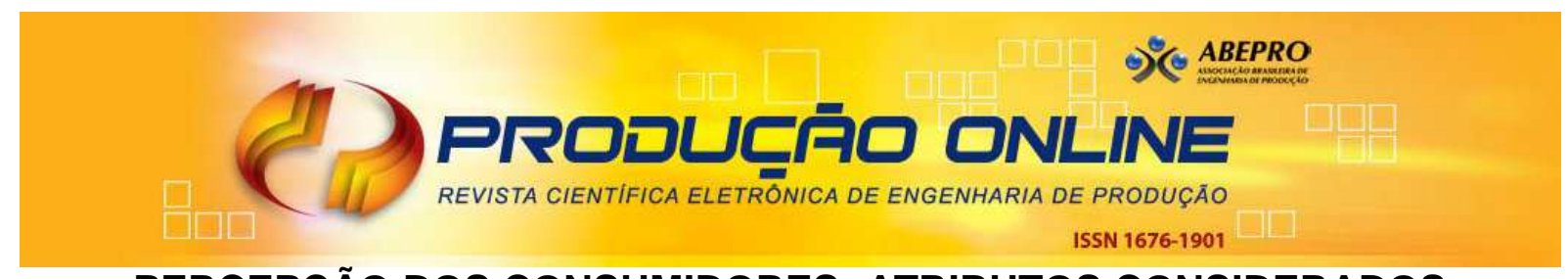

\title{
PERCEPÇÃO DOS CONSUMIDORES: ATRIBUTOS CONSIDERADOS IMPORTANTES NAS EMBALAGENS
}

\section{CONSUMER PERCEPTION: ATTRIBUTES CONSIDERED IMPORTANT IN PACKAGING}

\author{
Nara Medianeira Stefano*E-mail: stefano.nara@gmail.com \\ Nelson Casarotto Fillho* E-mail: casarotto@deps.ufsc.br \\ *Universidade Federal de Santa Catarina, UFSC, Florianópolis, SC
}

\begin{abstract}
Resumo: A embalagem vem sendo considerada o maior veículo de venda e de construção da marca e identidade do produto, uma vez que é o primeiro contato do consumidor com aquela mercadoria, sendo fundamental para a escolha e a compra do produto. Nesse sentido, a embalagem é o vendedor silencioso, pois cabe a ela atrair a atenção, provocar o interesse e o desejo, mostrar a qualidade do produto e fechar a venda em segundos. A embalagem contribuiu na comunicação das empresas com os consumidores; fornece proteção, armazenagem e conveniência, à medida que os produtos se movimentam na cadeia de valor. Pensando nisso, o produto não pode ser planejado separado da embalagem, e esta não deve ser definida apenas com base em engenharia, marketing, comunicação ou economia. O conceito de embalagem se ampliou e ganhou status de produto; a embalagem é capaz de comunicar uma mesma linguagem de conveniência onde quer que ela vá. Hoje, as indústrias de embalagens estão aproveitando esta oportunidade de diferenciação de seus produtos por meio das embalagens, percebendo que não basta a embalagem ser bonita, inviolável ou preservar o sabor e frescor dos alimentos. Dentro desse contexto, o objetivo desta pesquisa é analisar, na percepção dos consumidores, os atributos mais importantes com relação à embalagem dos produtos no momento da compra. Para tanto, os dados obtidos na pesquisa foram tratados por meio do software Statistica 8.0 e o SPSS 16 (Statistical Package Social Sciences).
\end{abstract}

Palavras-chave: Embalagens. Análise fatorial. Consumidor. Marca. Comunicação.

Abstract: Packaging has been considered the main vehicle for sales, brand building and product identity, since it is the first contact with the product that the consumer has, it is fundamental when choosing and buying a product. In this sense, the packaging is a silent salesperson, because it is up to the package to attract attention, create interest and desire, show the quality of the product and close the sale within seconds. Packaging has contributed to corporate communication with consumers; it provides product protection, storage and convenience, as products move through the value chain. Thinking about it, the product cannot be planned separately from its packaging, and it should not be defined based only on engineering, marketing, communications or economics. The packaging concept has expanded and gained product status; packaging is able to communicate the same language of convenience wherever it goes. Today, packaging industries are taking advantage of this opportunity to differentiate their products through packaging, finding that it is not enough for the package to be beautiful, unbreakable, or preserve the flavor and freshness of foods. Within this context, the objective of this research is to analyze, from the point of view of consumers, the most important product packaging attributes at the time of purchase. For this purpose, the data obtained in this study was run through the Statistica 8.0 and SPSS 16 (Statistical Package Social Sciences) software's.

Keywords: Packaging. Factor analysis. Consumer. Brand. Communication. 


\section{INTRODUÇÃO}

A embalagem acompanhou o homem desde os seus primórdios e, ao longo de sua evolução, colaborou para o desenvolvimento da indústria e da sociedade de consumo como um todo. $\mathrm{O}$ desenvolvimento de embalagens é uma atividade que vem se tornando cada vez mais importante na economia das nações, pelo fato de ter uma relação direta com praticamente todos os setores produtivos.

A importância da embalagem para a indústria de produtos de consumo é vital e insubstituível, principalmente porque desempenha o papel de representar 0 produto que acondiciona e, assim, embalagem e produto acabam se fundindo num só conceito. Isso está ocorrendo porque as empresas, ao perceberem que as embalagens podem representar a diferença entre os produtos, estão investindo fortemente nos elementos de design (forma, cores, materiais etc.), procurando estabelecer uma identidade própria para seus produtos.

É por meio das embalagens que milhões de pessoas em todo o mundo têm acesso a todos os tipos de produtos de consumo (JAHRE; HATTELAND, 2004; SILAYOI; SPEECE, 2007). Sem embalagens adequadas muitos dos alimentos que consumimos diariamente não fariam parte de nosso cardápio (PELEGRINI; KISTMANN, 2003). Na concepção do consumidor, a embalagem constitui um valor fundamental no momento da escolha do produto (VERNUCCIO; COZZOLINO; MICHELINI, 2010) e, devido a isso, as empresas investem cada vez mais nesta ferramenta de venda, adequando-se às exigências de seu público.

A indústria de embalagens é um setor fragmentado e diversificado, formado por um extenso complexo de mais de 100.000 empresas que empregam cerca de 5 milhões de pessoas em todo o mundo (PACKFORSK, 2001). Além da busca constante de materiais, a indústria passou a combinar matérias-primas. É o caso das caixas de cartão que, ao receberem uma camada de resina plástica, tornam-se impermeáveis e podem ser utilizadas para embalar líquidos (sucos, leite etc.). Há também as embalagens que possuem, em sua estrutura, materiais que permitem a conservação dos produtos por longos períodos.

As embalagens são projetadas (CHINEM; FLÓRIO, 2006) utilizando-se de uma linguagem visual com a pretensão e a intenção de "substituir" o vendedor, assumindo, dessa forma, um papel de forte mídia silenciosa que, por intermédio de 
seu design (RUNDH, 2009), conteúdo informativo, forma e linguagens gráficas, são capazes de agregar valores emocionais e funcionais.

Vários estudos (UNDERWOOD; KLEIN; BURKE, 2001; SILAYOI; SPEECE, 2004; LÖFGREN; WITELL, 2004 ROCCHI; STEFANI, 2005; LÖFGREN, 2006; SILAYOI; SPEECE, 2007; OGBA; JOHNSON, 2010; VENTER et al., 2010) têm sido realizados acerca da percepção dos consumidores com relação à embalagem dos produtos. O objetivo deste trabalho é analisar, na percepção dos consumidores, os atributos mais importantes com relação à embalagem dos produtos, no momento da compra.

Além desta introdução, o artigo apresenta: (i) o embasamento teórico; (ii) a metodologia da pesquisa; (iii) os resultados levantados; (iv) as considerações finais; e, por fim, (v) as referências utilizadas.

\section{EMBASAMENTO TEÓRICO}

Esta seção busca discutir aspectos relacionados: (i) às embalagens; (ii) ao panorama da indústria nacional de embalagens e (iii) à influência da embalagem na decisão de compra do consumidor.

\subsection{Embalagens}

Até por volta de 1900, a identificação dos produtos era realizada pela forma da embalagem - que não continha nomes, indicações de origem, imagens ou outros recursos visuais. As transações pautavam-se em relações de confiança entre comerciantes e consumidores (MOREIRA et al., 2004). Os rótulos de pano surgiram no século $X V$, e os de papel na virada do século XVIII para o XIX. A tecnologia utilizada no desenvolvimento de embalagens continuou a se aperfeiçoar nos anos 1970, somando-se à incrível variedade de estilos e ofertas (JAHRE; HATTELAND, 2004).

Segundo a Associação Brasileira de Embalagem (ABRE, 2008, 2009, 2010), no Brasil, até 1945, poucos produtos eram comercializados pré-acondicionados. $\mathrm{Na}$ indústria de alimentos, os principais eram o café torrado e moído, o açúcar refinado, o extrato de tomate, o leite em garrafa, o óleo de semente de algodão e o vinagre. A 
maioria dos produtos de primeira necessidade era vendida a granel, pesados no balcão e embrulhados em papel tipo manilha ou embalados em sacos de papel. Depois da Segunda Guerra Mundial, o processo de industrialização viabiliza a substituição de importações de produtos, impulsionando a demanda por embalagens tanto como invólucro direto dos produtos como embalagens direcionadas ao transporte de mercadorias.

A embalagem tornou-se um veículo, mais poderoso, de venda dos produtos na década de 1980, quando os designers perceberam que ela poderia ser integrada a uma concepção ampla da marca, veiculando uma mensagem global ao consumidor, de forma a integrar toda a comunicação empresarial. O crescimento da importância das embalagens, no final da década de 1990 e no início do novo milênio, se deu devido a algumas influências, como: autosserviço, influência dos consumidores, imagem da empresa e da marca e oportunidade de constante inovação (FARIA; SOUSA, 2008).

A embalagem é a única forma tangível de expressão da marca (LEE; LYE, 2003; 2003SILAYOI; SPEECE, 2004; WELLS; FARLEY; ARMSTRONG, 2007), corresponde à vinculação material com a empresa que fabrica o produto. As marcas (RETTIE; BREWER, 2000; SILAYOI; SPEECE, 2007) têm a função intrínseca de diferenciar, identificar o produto e, consequentemente, apontar o nível de qualidade do mesmo, facilitando o processo de escolha do consumidor.

A função de comunicação (UNDERWOOD; KLEIN; BURKE, 2001; SILAYOI; SPEECE, 2007; RUNDH, 2009; VERNUCCIO; COZZOLINO; MICHELINI, 2010) é a que permite levar a informação, utilizando diversas ferramentas, como símbolos, impressões e cores. Nas embalagens primárias, esta função ocorre diretamente com os consumidores finais, trazendo informações sobre a marca e o produto. Já nas embalagens ditas industriais, relacionadas à logística (RUNDH, 2005; GARCíAARCA; PRADO, 2008), a comunicação ocorre na medida em que alguns detalhes, como impressões de códigos de barra nas embalagens, marcações, cores (BORIN; CERF, 2011) ou símbolos, permitem a localização e identificação de forma facilitada nos processos logísticos de armazenagem, estoque, separação de pedidos e transporte.

Com o avanço da tecnologia, os materiais usados na fabricação das embalagens também foram contemplados com novidades surpreendentes, como a 
possibilidade de combinação dos mais variados tipos de matéria-prima (SINGH; GOYAL, 2010). Outro avanço é a impressão digital que permite melhor resolução e qualidade das embalagens, abre novas fronteiras para a utilização do potencial promocional e de marketing desse componente do produto. Muitos profissionais de marketing (JAHRE; HATTELAND, 2004; VERNUCCIO; COZZOLINO; MICHELINI, 2010) chamam a embalagem de o quinto "P" (do inglês, packaging), juntamente com produto, preço, praça e promoção. Pode-se afirmar que a embalagem é um item decisivo nesse novo cenário competitivo e deve-se extrair o máximo de seu potencial competitivo.

A embalagem é um meio e não um fim, isto é, ela não é um produto final em si, mas um componente do produto que ela contém. O produto (PRESAS; PRESAS, 2007) não pode ser planejado separadamente da embalagem, que, por sua vez, não deve ser definida apenas com base na engenharia, mas deve levar em conta aspectos como design, marketing (PRENDERGAST; PITT, 1996; GUSTAFSSON et al., 2006; VENTER et al., 2010; KUMAR; HONG; HAGGERTY, 2011) e comunicação; para alguns produtos, a forma e a função de sua embalagem pode ser quase tão importante quanto seu conteúdo.

$\mathrm{Na}$ criação de embalagens (PEREZ, 2004), os elementos de expressividade da marca são: as cores de fundo (KAUPPINEN-RÄISÄNEN; LUOMALA, 2010); isto é, o que ele representa na embalagem para o consumidor. Quando se acrescentam outros elementos - como cor, textura, pictogramas, imagens, formas - na criação da embalagem, consegue-se, na combinação desses elementos, uma massa gráfica visual que estabelece a identidade do produto. Os elementos isolados (PRESAS; PRESAS, 2007) não atribuem identidade a nenhum produto, mas o conhecimento e a criteriosa junção daqueles possibilitam que o designer de embalagem construa uma linguagem consistente.

$\mathrm{Na}$ atualidade, o consumidor faz a imagem do produto/empresa por meio da embalagem. Portanto, é aconselhável que as organizações desenvolvam soluções que englobem aspectos tangíveis (desenhos, formas, cores, tamanho) e intangíveis (reações, emoções) ao consumidor no momento da visualização da embalagem (RUNDH, 2009; GOLLETY; GUICHARD, 2011). 


\subsection{Panorama da indústria nacional de embalagens}

Conforme os dados da ABRE (2011), após recuar 3,77\% na produção entre 2008 e 2009, o segmento de embalagens registrou crescimento de $10,13 \%$ no ano de 2010, como é possível visualizar na Tabela 1. O desempenho do setor em 2011 deverá ser muito positivo, com estimativa de faturamento de $R \$ 44$ bilhões $-7 \%$ a mais que os $\mathrm{R} \$ 41,1$ bilhões de 2010 .

Tabela 1 - Faturamento da indústria de embalagem (em bilhões de $\mathrm{R} \$$ )

\begin{tabular}{c|cc}
\hline Ano & Receita Líquida de Vendas & Valor Bruto da Produção \\
\hline 2005 & 29,4 & 29,0 \\
2006 & 31,3 & 30,9 \\
2007 & 33,2 & 33,0 \\
2008 & 35,5 & 35,0 \\
2009 & 35,5 & 35,0 \\
2010 & 41,1 & 40,5 \\
\hline
\end{tabular}

Fonte: ABRE (2011)

O desempenho da indústria de embalagem é aferido pela produção física. Após recuo de $3,77 \%$ em 2009, decorrente dos efeitos da crise internacional, em 2010, a produção física registrou um crescimento de 10,13\%.

O setor registrou, em novembro de 2010, o nível recorde de 219.083 empregados com carteira assinada. Na comparação entre os dois anos (Figura 1), tendo por base a data final de cada período, o setor incorporou 13.167 novos postos de trabalho.

Figura 1 - Emprego formal na indústria nacional de embalagens

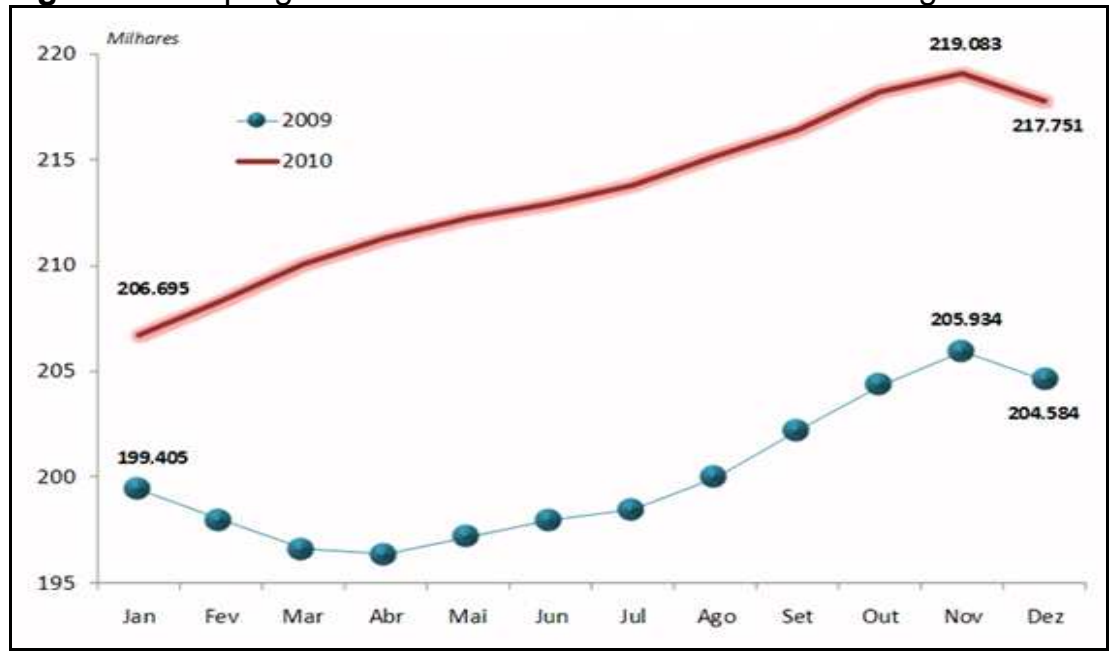

Fonte: ABRE (2011) 
A indústria nacional de embalagens gerou 14.943 postos de trabalho até junho de 2010, sendo que o número de pessoas empregadas pelo setor totalizou 208.776, contra 193.833 de 2009 (ABRE, 2011). A Figura 2 mostra o desempenho das exportações da indústria de embalagens.

Figura 2 - Exportações de embalagem Brasil/2010

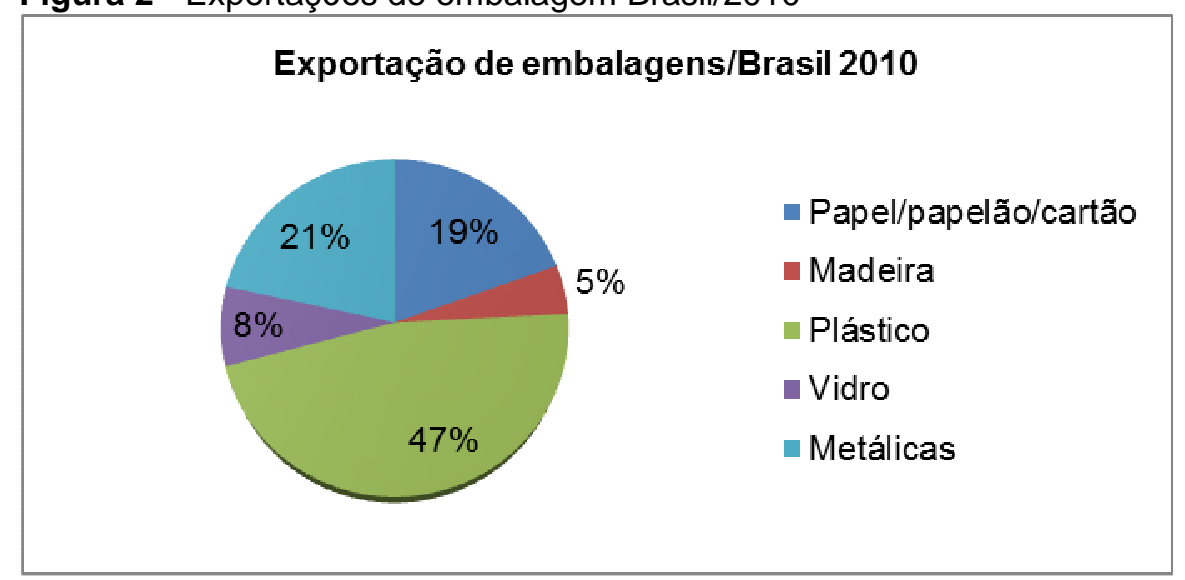

Fonte: ABRE (2011)

A indústria nacional de embalagens registrou no ano de 2010 US\$ 410,11 milhões nas exportações - 16,7\% a mais que em 2009 (US\$ 351,410 milhões). As importações cresceram 70\% em 2010, atingindo US $\$ 794,05$ milhões (ante os US\$ 467,1 milhões de 2009). Segundo dados da ABRE (2011), o principal motivo para essa ascensão significativa nas importações foi o aumento das compras de embalagens metálicas (que aumentaram 234,8\%) para abastecer o mercado interno, estimulado pela alta no consumo de bebidas. A capacidade produtiva interna alcançou o seu limite, e as indústrias nacionais estão em um processo de aumento de investimento para atender a alta demanda.

Logo, a dimensão do mercado adicionada à necessidade de atender clientes de vários setores e à disponibilidade de uma extensa gama de tecnologias, materiais e processos, direcionam o posicionamento estratégico dos fabricantes de embalagens. Esses aspectos são imprescindíveis e dividem as empresas em nichos e segmentos especializados num determinado tipo de material, processo, produto ou cliente. 


\subsection{Influência da embalagem na decisão de compra do consumidor}

A embalagem passou a representar um meio de contato, comunicação e conquista junto ao consumidor final, possuindo exclusivamente as características de contato direto, tátil, sensorial e intelectual com seu usuário. No processo decisório de compra do consumidor (NEVES; CASTRO, 2007), a embalagem aparece como um item relevante quanto à percepção do produto. $O$ consumidor está mais consciente da relação custo-benefício dos produtos e tem seus direitos assegurados pelo Código do Consumidor.

Muitas vezes, a escolha por uma embalagem envolve aspectos subjetivos e, nesse momento, o consumidor transfere o conteúdo da imagem externa para seu inconsciente, formando sua percepção, ou seja, o comportamento do consumidor. Em um ultimo estágio, onde a marca (WELLS; FARLEY; ARMSTRONG, 2007; ZAYER; NEIER, 2011) e a embalagem encontram-se totalmente associadas, o consumidor passa a identificá-las como um símbolo e desenvolve, assim, uma relação mais estreita com o produto.

O entendimento do comportamento do consumidor é definido como as atividades físicas e mentais realizadas por clientes de bens de consumo e industriais que resultam em decisões e ações, como comprar e utilizar produtos e serviços, bem como pagar por eles (SHETH; MITTAL; NEWMAN, 2001). O consumidor é influenciado por aspectos culturais, sociais, individuais e psicológicos, segundo Kotler (1998):

a) culturais: a cultura é o determinante mais fundamental dos desejos e do comportamento de uma pessoa;

b) sociais: os grupos de referência de uma pessoa compreendem todos os grupos que têm influência direta ou indireta sobre as atitudes ou comportamento da pessoa;

c) pessoais: incluem a idade e o estágio do ciclo de vida, ocupação, situação econômica, estilo de vida, personalidade e autoestima;

d) psicológicos: motivação, percepção, aprendizagem, crenças e atitudes são importantes e influenciam nas decisões de compra de uma pessoa. 
Os consumidores, normalmente, passam por sete estágios de tomada de decisão (BLACKWELL; ENGEL; MINIARD, 2005):

a) reconhecimento da necessidade: os consumidores compram coisas quando acreditam que a habilidade do produto em solucionar problemas vale mais que o custo de comprá-lo;

b) busca de informações: reconhecida a necessidade, os consumidores começam a buscar informações e soluções para satisfazer as suas necessidades não atendidas;

c) avaliação de alternativa pré-compra: os consumidores comparam o que conhecem sobre diferentes produtos e marcas com o que consideram mais importantes e começam a estreitar o campo de alternativas antes de finalmente resolverem comprar umas delas;

d) compra: depois de se decidir sobre a compra, os consumidores passam por duas fases. Na primeira eles escolhem um vendedor em vez de outro (ou qualquer outra forma de varejo, como catálogos). A segunda fase envolve escolhas dentro da loja influenciadas pelo vendedor, pelas vitrines, meios eletrônicos e propagandas no ponto-de-venda;

e) consumo: a forma como o produto é utilizado pelos consumidores também afeta quão satisfeitos eles estão com as compras e quando vão comprar essa marca ou produto novamente;

f) avaliação pós-consumo: a satisfação ocorre quando a performance percebida confirma ou ultrapassa as expectativas dos consumidores; quando experiências e performance frustram expectativas, a insatisfação ocorre. As emoções desempenham papel na avaliação de um produto ou transação (PENSZ; HOGG, 2011);

g) descarte: é o último estágio no modelo do processo de decisão do consumidor. Os consumidores têm várias opções, incluindo descarte completo, reciclagem ou revenda.

Compreendendo os estágios, dentro do mapa de tomada de decisão do consumidor, profissionais de marketing podem descobrir o porquê as pessoas compram, ou não, produtos e fazer com que essas pessoas comprem mais de um fornecedor específico. 


\section{PROCEDIMENTOS METODOLÓGICOS}

Esta seção do trabalho aborda os procedimentos para coleta e análise dos dados.

\subsection{Enquadramento metodológico}

O embasamento teórico deste trabalho fundamentou-se na base de dados existente no portal da CAPES (Coordenação de Aperfeiçoamento do Pessoal do Ensino Superior). Para fins do estudo a respeito da percepção dos clientes quanto aos itens mais importante no momento da compra com relação à embalagem dos produtos, foram realizadas entrevistas com uma amostra não probalística por conveniência. Em setembro de 2008, foram entrevistados 363 consumidores em dois supermercados em Porto Alegre (RS). Os supermercados foram selecionados com base na sua localização, em bairros de classe média-alta, e em virtude do público que atingem: classes A e B. A amostra foi realizada por conveniência e aleatoriamente.

As entrevistas foram divididas em duas partes. Na primeira, consideraram-se as variáveis demográficas, tais como: gênero, idade, escolaridade, renda e o número de pessoas com quem residem. No segundo momento, procurou-se caracterizar os principais atributos quanto à embalagem, levados em consideração no momento da compra do consumidor. $O$ instrumento utilizado para a coleta dos dados, no segundo momento, foi um questionário composto por questões fechadas. As questões foram estruturadas de acordo com o modelo de escala de Likert, onde as opções variavam de 1 a 5, sendo 1 o ponto de menor e 5 o de maior importância: (1) Sem Importância; (2) Pouco Importante; (3) Indiferente; (4) Muito Importante; (5) Extremamente Importante.

No questionário foram utilizadas 19 questões aplicadas aos 363 consumidores, como pode ser visualizado no Quadro 1: 
Quadro 1 - Itens (atributos) que compuseram o questionário da pesquisa

\begin{tabular}{|c|c|}
\hline Atributo/abreviatura & Descrição \\
\hline Qualidade (QUALI) & Qualidade da embalagem. \\
\hline $\begin{array}{l}\text { Material com que é feita } \\
\text { (MAT) }\end{array}$ & Material na confecção da embalagem. \\
\hline Rótulo (ROT) & $\begin{array}{l}\text { Informações verbais e não verbais, contidas nos rótulos da } \\
\text { embalagem, são denotativas quando mostram informações } \\
\text { técnicas e/ou nutricionais; e conotativas, como cores, imagens, } \\
\text { texturas, entre outras. }\end{array}$ \\
\hline $\begin{array}{l}\text { Legibilidade das letras, } \\
\text { símbolos e etc. (LEGI) }\end{array}$ & $\begin{array}{l}\text { Legibilidade da letra utilizada, símbolos e fotos utilizados no } \\
\text { rótulo. }\end{array}$ \\
\hline $\begin{array}{l}\text { Manter as características do } \\
\text { produto (MACP) }\end{array}$ & $\begin{array}{l}\text { Capacidade de manter as características físicas, químicas, } \\
\text { microbiológicas e organolépticas dos produtos pelo período de } \\
\text { tempo requerido, evitando ou minimizando as perdas. }\end{array}$ \\
\hline Design & balagem. \\
\hline Comuni & $\begin{array}{l}\text { tir a informação, por meio dos } \\
\text { rrma, dimensão, cor, gráficos, sím }\end{array}$ \\
\hline Tamant & emba \\
\hline (REC) & cláveis \\
\hline Estilo ( & Es \\
\hline Logomarca (LOGO) & $\begin{array}{l}\text { a, símbolos estampados nos rótulos das embalagens, } \\
\text { arca. }\end{array}$ \\
\hline Higiêni & $\begin{array}{l}\text { Capacidade de a embalagem proporcionar uso higiênico, } \\
\text { evitando vazamentos, e de ser asséptica. }\end{array}$ \\
\hline Ergonômica (ERG) & $\begin{array}{l}\text { Fato de a embalagem possuir formato ergonômico para } \\
\text { consumidores com necessidades especiais. }\end{array}$ \\
\hline $\begin{array}{l}\text { Praticidade e conveniência } \\
\text { (PRACO) }\end{array}$ & Praticidade de abrir, fechar e retampar a embalagem. \\
\hline Cor do rótulo (CORR) & $\begin{array}{l}\text { Cor do rótulo que facilita a visualização das demais informações } \\
\text { sobre o produto. }\end{array}$ \\
\hline Custo/benefício (CUS/BEM) & $\begin{array}{l}\text { ou não adquiridos pelo preço pago pela } \\
\text { ado produto. }\end{array}$ \\
\hline Funcionalidade (FUNC) & $\begin{array}{l}\text { Manuseabilidade, adequação e conforto na utilização do produto, } \\
\text { principalmente para aqueles que são utilizados nas próprias } \\
\text { embalagens. }\end{array}$ \\
\hline $\begin{array}{l}\text { Prolongar a validade do } \\
\text { produto (PVPR) }\end{array}$ & Capacidade da embalagem de prolongar a vida útil do produto. \\
\hline Segurança (SEG) & $\begin{array}{l}\text { A capacidade da embalagem de } \mathrm{pr} \\
\text { influencias físicas ou químicas. }\end{array}$ \\
\hline
\end{tabular}

Fonte: Elaborado pelos autores.

Foi utilizada a análise fatorial para tratar os dados, a qual identifica um conjunto menor de variáveis hipotéticas (fatores), com o objetivo de reduzir a dimensão dos dados e possibilitar o agrupamento em fatores, de acordo com seu comportamento, sem perda de informação do conjunto inicial. Parte da estrutura de dependência existente entre as variáveis de interesse (em geral representada pelas correlações ou covariâncias entre elas) permite a criação de um conjunto menor (variáveis latentes ou fatores) obtido em função das variáveis originais. Também é possível saber o quanto cada fator está associado a cada variável e o quanto 0 conjunto de fatores explica a variabilidade geral dos dados originais.

A mensuração da adequação da aplicação da análise fatorial para Revista Produção Online, Florianópolis, SC, v.12, n. 3, p. 657-681, jul./set. 2012. 
determinado conjunto de dados foi realizada por meio de dois testes: Kaiser-MeyerOlkin (KMO) e teste de esfericidade de Bartlett (HAIR et al., 2006). O teste KaiserMeyer-Olkin (KMO) indica a proporção da variância dos dados que pode ser considerada comum a todas as variáveis, isto é, que pode ser atribuída a um fator comum. Então, quanto mais próximo de 1 (unidade), melhor o resultado, ou seja, mais adequada é a amostra à aplicação da análise fatorial. Em outras palavras, este teste indica se a análise fatorial é apropriada ou não.

O teste de esfericidade de Bartlett verifica se a matriz de correlação é uma matriz identidade, o que indicaria que não há correlação entre os dados. Assim, procura-se, para um nível de significância assumido em 5\%, rejeitar a hipótese nula de matriz de correlação identidade. Valores de significância (HAIR et al., 2006) maiores que 0,100 indicam que os dados não são adequados para tratamento com o método em questão; que a hipótese nula não pode ser rejeitada. Valores menores que o indicado permitem rejeitar a hipótese nula.

\section{ANÁLISE DOS RESULTADOS}

A seção 4 do trabalho apresenta a análise referente aos dados da pesquisa.

\subsection{Análise das variáveis demográficas}

Dos entrevistados, 55\%, isto é, 198 consumidores, são do gênero feminino, e 45\% (165) são masculinos. A idade dos entrevistados está representada na Tabela 2. Observa-se que a maioria (22\%) encontra-se na faixa de 36 a 40 anos e o menor percentual (3\%) é o de pessoas na faixa de 56 a 60 anos.

\begin{tabular}{l|l}
\multicolumn{2}{l}{ Tabela 2 - Faixa etária dos entrevistados } \\
\hline Idade & Percentual (\%) \\
\hline Entre 16 e 20 anos & 9 \\
Entre 21 e 25 anos & 14 \\
Entre 26 e 30 anos & 11 \\
Entre 31 e 35 anos & 22 \\
Entre 36 e 40 anos & 21 \\
Entre 41 e 45 anos & 8 \\
Entre 46 e 50 anos & 4 \\
Entre 51 e 55 anos & 5 \\
Entre 56 e 60 anos & 3 \\
Acima de 60 anos & 3 \\
Total & $\mathbf{1 0 0 , 0 0}$ \\
\hline
\end{tabular}

Fonte: Elaborado pelos autores. 
$\mathrm{Na}$ Tabela 3, constam as informações a respeito da escolaridade dos entrevistados. Observa-se que a maioria - $22 \%$ - possui ensino superior completo.

Tabela 3- Escolaridade dos entrevistados

\begin{tabular}{l|c}
\hline \multicolumn{1}{c|}{ Escolaridade } & Percentual \\
\hline Ensino fundamental incompleto & 1 \\
Ensino fundamental completo & 7 \\
Ensino médio incompleto & 6 \\
Ensino médio completo & 10 \\
Ensino superior incompleto & 18 \\
Ensino superior completo & 22 \\
Pós-Graduação incompleta & 21 \\
Pós-Graduação completa & 15 \\
\multicolumn{1}{c}{ Total } & $\mathbf{1 0 0 , 0 0}$ \\
\hline
\end{tabular}

Fonte: Elaborado pelos autores.

É possível verificar, na Tabela 4, a renda dos entrevistados: a maioria (34\%) encontra-se concentrada na faixa de até 10 salários mínimos.

Tabela 4 - Renda dos entrevistados

\begin{tabular}{c|l}
\hline \multicolumn{1}{c|}{ Renda } & Percentual (\%) \\
\hline Até 3 salários mínimos & 7 \\
Até 5 salários mínimos & 7 \\
Até 7 salários mínimos & 13 \\
Até 10 salários mínimos & 34 \\
Até 13 salários mínimos & 2 \\
Mais de 13 salários mínimos & 17 \\
Total & $\mathbf{1 0 0}$ \\
\hline
\end{tabular}

Fonte: Elaborado pelos autores.

Na seção a seguir é apresentada a discussão da análise fatorial realizada neste trabalho.

\subsection{Análise fatorial}

Considerando a presença de correlações significantes ao nível de 0,05 , foi examinada a coerência interna entre as 19 variáveis, utilizando-se o Alpha de Cronbach (Tabela 5), que originou um valor igual a 0,74189 , demonstrando a boa confiabilidade das respostas atribuídas às questões. 
Tabela 5 - Confiabilidade Alpha de Cronbach

\begin{tabular}{c|lccc}
\hline Atributo & $\begin{array}{c}\text { Média, se } \\
\text { deletado o } \\
\text { atributo }\end{array}$ & $\begin{array}{c}\text { Variância, se } \\
\text { deletado o } \\
\text { atributo }\end{array}$ & $\begin{array}{c}\text { Desvio padrão, } \\
\text { se deletado o } \\
\text { atributo }\end{array}$ & $\begin{array}{c}\text { Alpha, se deletado } \\
\text { o atributo }\end{array}$ \\
\hline QUALI & 80,32783 & 27,54267 & 5,248111 & 0,733063 \\
MAT & 80,91184 & 24,37790 & 4,937398 & 0,712538 \\
DESI & 80,42975 & 27,31393 & 5,226274 & 0,733658 \\
MACP & 80,41322 & 26,74385 & 5,171445 & 0,724953 \\
PRACO & 80,48485 & 25,42883 & 5,042701 & 0,713696 \\
FUNC & 81,24518 & 23,95366 & 4,894248 & 0,722804 \\
CUST/BENE & 80,58678 & 26,69426 & 5,166649 & 0,731969 \\
COMU & 80,64188 & 26,26293 & 5,124737 & 0,728138 \\
REC & 80,86777 & 26,10924 & 5,109720 & 0,741416 \\
HIG & 80,38017 & 28,03729 & 5,295025 & 0,740863 \\
SEGU & 80,38843 & 27,61496 & 5,254994 & 0,735087 \\
PVPR & 80,49862 & 26,64118 & 5,161510 & 0,725152 \\
LOGO & 80,70799 & 25,45192 & 5,044990 & 0,721599 \\
EST & 81,01929 & 25,04371 & 5,004369 & 0,723874 \\
ROT & 80,45730 & 26,65589 & 5,162934 & 0,724683 \\
LEGI & 80,54270 & 27,57049 & 5,250761 & 0,744742 \\
TAM & 80,71901 & 26,95135 & 5,191469 & 0,742003 \\
ERG & 80,68595 & 27,50468 & 5,244490 & 0,746278 \\
CORR & 80,67493 & 27,27174 & 5,222235 & 0,744097 \\
\hline Alpha de Cronbach & & $\mathbf{0 , 7 4 1 8 9 3 6 9 0}$ & \\
Alpha de Cronbach Padronizado & $\mathbf{0 , 7 6 3 4 7 4 9 5 0}$ & \\
\hline
\end{tabular}

Fonte: Elaborado pelos autores.

O teste de confiabilidade é imperativo e mede o desempenho de um instrumento em uma dada população, evitando o agrupamento de questões aparentemente relevantes. Na Tabela 6, foram agrupadas as variáveis pesquisadas, denominadas fatores, que descrevem a importância dos clientes acerca de itens relacionados à embalagem dos produtos. A partir da geração da fatorial, seis fatores foram obtidos com autovalor acima de 1 (critério da raiz latente). Os seis fatores equivalem a uma explicação de 63,13\% (variância acumulada), aproximadamente, da variabilidade total dos dados.

$\mathrm{Na}$ análise por meio do teste de Kaiser-Meyer-Olkin (KMO) foi encontrado um valor de 0,736, indicando adequação dos dados à análise. No teste de esfericidade de Bartlett, obteve-se, com a aproximação, um valor de 2.172,345 com 171 graus de liberdade e nível de significância de $p<0,0001$, rejeitando-se a hipótese nula de que a matriz de correlação é uma matriz identidade. 
Tabela 6 - Autovalores, percentual de variância explicada e comunalidades pelo Método de Análise dos Componentes Principais (ACP)

\begin{tabular}{c|ccccc}
\hline Fator & Autovalor & $\begin{array}{c}\text { \% Variância } \\
\text { Explicada }\end{array}$ & $\begin{array}{c}\text { Autovalor } \\
\text { Acumulado }\end{array}$ & $\begin{array}{c}\text { \%Variância } \\
\text { Acumulada }\end{array}$ & Comunalidades \\
\hline $\mathbf{1}$ & $\mathbf{4 , 0 1 0}$ & $\mathbf{2 1 , 1 0 7}$ & $\mathbf{4 , 0 1 0}$ & $\mathbf{2 1 , \mathbf { 1 0 7 }}$ & 0,615 \\
$\mathbf{2}$ & $\mathbf{2 , 1 6 7}$ & $\mathbf{1 1 , 4 0 5}$ & $\mathbf{6 , 1 7 7}$ & $\mathbf{3 2 , 5 1 2}$ & 0,878 \\
$\mathbf{3}$ & $\mathbf{2 , 0 7 1}$ & $\mathbf{1 0 , 9 0 0}$ & $\mathbf{8 , 2 4 8}$ & $\mathbf{4 3 , 4 1 2}$ & 0,665 \\
$\mathbf{4}$ & $\mathbf{1 , 4 2 6}$ & $\mathbf{7 , 5 0 6}$ & $\mathbf{9 , 6 7 4}$ & $\mathbf{5 0 , 9 1 8}$ & 0,594 \\
$\mathbf{5}$ & $\mathbf{1 , 2 7 8}$ & $\mathbf{6 , 7 2 6}$ & $\mathbf{1 0 , 9 5 2}$ & $\mathbf{5 7 , 6 4 4}$ & 0,673 \\
$\mathbf{6}$ & $\mathbf{1 , 0 4 3}$ & $\mathbf{5 , 4 8 8}$ & $\mathbf{1 1 , 9 9 5}$ & $\mathbf{6 3 , 1 3 2}$ & 0,764 \\
$\mathbf{7}$ & 0,986 & 5,188 & 12,981 & 68,320 & 0,383 \\
$\mathbf{8}$ & 0,818 & 4,307 & 13,799 & 72,627 & 0,520 \\
9 & 0,813 & 4,280 & 14,612 & 76,907 & 0,7987 \\
10 & 0,692 & 3,640 & 15,304 & 80,574 & 0,454 \\
11 & 0,621 & 3,270 & 15,925 & 83,817 & 0,717 \\
12 & 0,558 & 2,939 & 16,483 & 86,746 & 0,468 \\
13 & 0,529 & 2,786 & 17,012 & 89,532 & 0,835 \\
14 & 0,467 & 2,457 & 17,479 & 91,989 & 0,802 \\
15 & 0,450 & 2,366 & 17,857 & 94,355 & 0,601 \\
16 & 0,378 & 1,988 & 18,235 & 96,350 & 0,670 \\
17 & 0,350 & 1,845 & 18,585 & 98,196 & 0,344 \\
18 & 0,212 & 1,115 & 18,797 & 99,311 & 0,658 \\
19 & 0,131 & 0,689 & 18,928 & 100,00 & \\
\hline
\end{tabular}

Fonte: Elaborado pelos autores.

Conhecendo os autovalores, determinaram-se os autovetores, que compõem a base para a obtenção dos fatores. Através deles é possível escrever a combinação linear das variáveis originais, o que dará origem às cargas fatoriais. $\mathrm{Na}$ Tabela 7 , são demonstradas as cargas fatoriais que representam a contribuição de cada atributo (variável) para a formação do fator. Utilizou-se o Método de Rotação VARIMAX dos fatores para melhorar visualizar as cargas fatoriais representativas em cada fator.

Tabela 7- Cargas fatoriais

\begin{tabular}{c|llllll}
\hline Atributo & \multicolumn{1}{|c}{ Fator 1 } & \multicolumn{1}{c}{ Fator 2 } & \multicolumn{1}{c}{ Fator 3 } & Fator 4 & \multicolumn{1}{c}{ Fator 5 } & Fator 6 \\
\hline QUALI & 0.022909 & -0.045462 & 0.197966 & 0.057418 & $\mathbf{0 . 7 5 4 6 5 4}$ & -0.018943 \\
MAT & 0.087024 & 0.031127 & $\mathbf{0 . 9 0 8 7 9 9}$ & 0.178468 & 0.052107 & 0.094304 \\
DESI & 0.139494 & -0.004224 & -0.065739 & 0.048735 & $\mathbf{0 . 7 9 8 2 2 4}$ & 0.034659 \\
MACP & $\mathbf{0 . 6 8 6 4 7 9}$ & 0.073417 & 0.041740 & -0.042999 & 0.185674 & 0.282054 \\
PRACO & $\mathbf{0 . 7 5 4 7 0 9}$ & 0.013297 & 0.170905 & 0.210331 & 0.007358 & 0.172524 \\
FUNC & 0.166298 & 0.019388 & 0.181035 & $\mathbf{0 . 8 2 3 4 7 0}$ & 0.042264 & 0.152270 \\
CUST/BENE & 0.176404 & -0.055782 & 0.141316 & 0.114024 & 0.316138 & 0.464558 \\
COMU & $\mathbf{0 . 6 6 5 8 7 9}$ & 0.041622 & 0.184214 & -0.191705 & 0.053760 & 0.029908 \\
REC & -0.019648 & -0.001781 & 0.054450 & $\mathbf{0 . 8 8 6 7 9 7}$ & 0.087788 & -0.006659 \\
HIG & -0.053940 & -0.014278 & 0.166670 & -0.011266 & -0.080535 & $\mathbf{0 . 7 2 0 4 2 0}$ \\
SEGU & 0.313922 & -0.092812 & -0.057123 & 0.106663 & -0.008162 & $\mathbf{0 . 5 7 6 5 2 5}$ \\
PVPR & $\mathbf{0 . 8 4 3 4 4 1}$ & 0.014537 & 0.031855 & 0.065776 & 0.009229 & -0.016496 \\
LOGO & 0.242319 & 0.063839 & $\mathbf{0 . 5 4 6 8 5 1}$ & -0.072047 & 0.157557 & 0.275436 \\
EST & 0.034625 & 0.017751 & $\mathbf{0 . 9 0 4 5 3 7}$ & 0.123375 & 0.012346 & -0.005254 \\
ROT & $\mathbf{0 . 8 7 6 6 5 7}$ & -0.050424 & -0.041315 & 0.155310 & 0.071161 & 0.012702 \\
LEGI & -0.005975 & $\mathbf{0 . 7 6 5 0 6 8}$ & 0.050807 & -0.072238 & -0.021788 & -0.087625 \\
TAM & 0.106739 & $\mathbf{0 . 8 0 9 6 2 6}$ & -0.020325 & -0.034214 & -0.016582 & -0.032387 \\
ERG & 0.026553 & $\mathbf{0 . 5 1 5 9 4 4}$ & 0.160540 & 0.057880 & -0.169967 & -0.139657 \\
CORR & -0.074381 & $\mathbf{0 . 7 7 2 5 7 5}$ & -0.095602 & 0.073282 & 0.138576 & 0.147213 \\
\hline
\end{tabular}

Fonte: Elaborado pelos autores. 
Posteriormente, foram realizados os planos fatoriais entre os fatores. O plano fatorial permite considerar a importância de cada atributo na constituição de cada fator e colabora para o conhecimento da estrutura das inter-relações das variáveis. As variáveis representativas em cada fator estão destacadas por círculos para promover melhor visualização.

Dentre os 6 fatores, somente o Fator 1 contribui com 21,10\% da variabilidade total dos dados. O Fator 1 mostra, com maior representatividade, as variáveis ROT (rótulo das embalagens) e PVPR (prolongar a validade do produto) com carga fatorial de 0.8766 e 0.8434 , respectivamente. Esses atributos foram classificados como extremamente importante e importante na percepção dos consumidores. O rótulo (SCATOLIM, 2006) permite o reconhecimento e a identidade visual do produto, traz informações sobre ingredientes, a finalidade do produto, o modo de uso, e, além do aspecto informacional, também agrega valores estéticos à mercadoria.

Quanto ao atributo PVPR (prolongar a validade do produto), salienta-se que as embalagens ativas (PEREZ, 2008) têm a função de prolongar a vida útil dos alimentos (URALA; LÄHTEENMÄKI, 2004 SIEGRIST; STAMPFLI; KASTENHOLZ, 2008; OZIMEK; ZAKOWSKA-BIEMANS, 2011) e, ao mesmo tempo, aumentar a competitividade dos produtos brasileiros. Essas são as funções das chamadas embalagens ativas, que possuem aditivos que interagem com os produtos para manter a qualidade e aumentar o tempo de prateleira. Ainda segundo Perez (2008) o oxigênio interage com gorduras, vitaminas e pigmentos, oxidando-os. $\mathrm{O}$ aditivo pode ser utilizado na forma de sache ou incorporado diretamente no material polimérico da embalagem e tem como função a absorção tanto do oxigênio residual, que permanece na embalagem mesmo quando se usa o vácuo, quanto do oxigênio, que consegue entrar na mesma.

Quanto ao Fator 2, este contribui com $11,40 \%$ da variabilidade total dos dados, mostrando maior representatividade nos atributos TAM (tamanho da embalagem) e CORR (cor do rótulo), ambos com carga fatorial de 0,8096 e 0,7725, respectivamente, classificados como muito importante e importante no ponto de vista dos consumidores. O formato está diretamente ligado ao aspecto funcional da embalagem, pois uma embalagem muito grande ou de formato desconfortável pode, além de ser um transtorno ao consumidor, gerar, inclusive, preferência por uma 
marca concorrente.

Corroborando com os resultados da pesquisa com relação ao atributo tamanho (TAM), Gonçalves, Passos e Biedrzycki (2008) colocam que, devido à oferta cada vez maior de tipos variados de produtos dentro de uma mesma linha, verifica-se a tendência voltada para a criação de embalagens menores, pois os espaços reduzidos nas prateleiras dos supermercados deverão ser repartidos por um número cada vez maior de produtos. Com isso, amplia-se a necessidade de diferenciação dos produtos e, consequentemente, ganham mais relevância itens como conveniência e funcionalidade das embalagens. Há que se considerar que a redução do tamanho das embalagens é forçada pela redução do tamanho das famílias.

Quanto à importância da cor do rótulo (COOR), Gonçalves, Passos e Biedrzycki (2008) mencionam que as embalagens, também, devem considerar as necessidades da população idosa, particularmente a facilidade de abertura e a legibilidade do rótulo. Para satisfazer esta necessidade, a indústria estipula um tamanho mínimo permitido de letra. É desejável também que as cores (BORIN; CERF, 2011) utilizadas permitam a máxima legibilidade. As primeiras cores que os idosos deixam de ver são azul e verde, enquanto vermelho, laranja e dourado permanecem por mais tempo.

Um estudo desenvolvido por Markovina et al. (2011), a respeito da percepção do consumidor jovem quanto aos alimentos funcionais (produtos lácteos, frutas e legumes) na Croácia, mostra que as formas usuais para os consumidores identificarem os alimentos funcionais são: rótulos (37\%); comerciais (34\%); embalagens (15\%); aparência (9\%) e marca ( $8 \%)$. Isso demonstra a importância do rótulo nas embalagens.

O Fator 3 colabora com 10,90\% da variabilidade total dos dados. As variáveis de maior relevância neste fator são: EST (estilo), LOGO (logomarca) e MAT (material com que é feita a embalagem), todas com carga fatorial de $0.9045,0,5446$ e 0.9087, respectivamente, e classificadas como extremamente importante. Com relação ao estilo, Baxter (1998) coloca que, quando se fala de um produto atrativo, raramente se refere ao seu som, cheiro ou tato. A percepção humana é amplamente dominada pela visão, e, quando se fala em estilo, refere-se ao seu estilo visual, pois o sentido visual é predominante sobre os demais. A atratividade de um produto 
depende, essencialmente, do aspecto visual da embalagem.

A percepção visual (MASON; ROBINSON, 2011) impressiona e, em primeira instância, provoca assimilações e análises, dependendo de diversos aspectos cognitivos (ligados à memória). A motivação para a compra está sujeita a itens extrínsecos, que levam a conhecer o novo; e intrínsecos, que dependem da atividade intelectual que motivará a pessoa, levando em consideração vários contextos epistemológicos, de características individuais, relacionados à interpretação.

O Fator 4 representa $7,50 \%$ do total da variabilidade dos dados, com destaque para as variáveis FUN (funcionalidade da embalagem) e REC (embalagem ser reciclável), com as respectivas cargas fatoriais de 0,8234 e 0,8867. $\mathrm{Na}$ atualidade, a exigência do consumidor é por embalagens funcionais (SINGH; GOYAL, 2010; SINGH; WANI, 2011), em termos de: comunicação de informações claras e objetivas a respeito do seu conteúdo; detalhes da fabricação do produto; formas de manipulação; fechamento e refechamento para uma correta conservação do alimento; entre demais características.

Sistemas de fácil abertura de tampas metálicas para latas e frascos de vidro são mais alguns exemplos da tentativa de se criar embalagens funcionais para o acondicionamento de alimentos, evitando-se a contaminação e possibilitando uma melhor conservação, prolongando-se, muitas vezes, a possibilidade de consumo deste produto (EMBALAGEM \& CIA, 2001).

Quanto ao fato da embalagem ser reciclável, salienta-se que o aumento da consciência ecológica, em nível mundial, tem impulsionado a produção de embalagens recicláveis de refis (BUELOW; LEWIS; SONNEVELD, 2010) que, ao serem descartadas, podem ser amassadas, reduzindo dessa forma, o espaço ocupado em aterros sanitários. Nos países desenvolvidos, já se observam problemas relacionados ao espaço físico necessário para deposição dos entulhos.

O Fator 5 apresenta $6,76 \%$ do total da variabilidade dos dados, com destaque para as variáveis DESI (design da embalagem) e QUALI (qualidade da embalagem), com as respectivas cargas fatoriais de 0,7982 e 0,7546. O design é um componente decisivo no novo cenário competitivo (GOFMAN; MOSKOWITZ, 2010; MASON; ROBINSON, 2011). Ele agrega valor e significado ao produto, constituindo-se em um diferencial fundamental. O design da embalagem é responsável pela diferenciação 
do produto (BARTHOLME; MELEWAR, 2011), criando o impacto visual necessário para a sua identificação, atraindo o consumidor e constituindo um contato emocional com este. Com relação à qualidade das embalagens, é importante destacar que, em meio ao mercado cada vez mais competitivo, torna-se essencial a aplicação do controle de qualidade em todas as etapas de produção para evitar desperdícios e garantir a qualidade do produto. Na área do empacotamento, é indispensável que se façam análises nas embalagens, como de vedações de pacotes e gramatura, para evitar a diminuição da vida de prateleira do produto e/ou desperdícios de embalagens.

Para o usuário, evidentemente, o ideal seria uma embalagem sem defeitos (SARANTÓPOULOS et al., 2002), mas isso teria uma influência muito grande nos custos. Uma embalagem com qualidade muito alta apresenta também um custo muito elevado (BUELOW; LEWIS; SONNEVELD, 2010), o que a torna inviável economicamente. Assim, o que se procura fazer é alcançar um máximo de qualidade possível dentro de uma faixa de custo viável, ou seja, o custo passa a ser limitante do nível de qualidade da embalagem.

Os atributos que formam o Fator 6, isto é, HIG (higiene) e SEGU (segurança), apresentam carga fatorial 0,7204 e 0,5765, respectivamente. A embalagem deve, antes de tudo, oferecer proteção contra danos que ocorrem no transporte e distribuição, tais como choques, impactos, vibração e compressão. Quando a proteção que a embalagem oferece não é adequada, há perda parcial ou mesmo total de produto que não chega a ser consumido.

A embalagem desempenha um papel fundamental na segurança do produto (POÇAS; MOREIRA, 2003), na medida em que previne ou evidencia a abertura ou intrusão, o que pode significar adulteração ou perda de integridade do produto. Essa perda de integridade pode ser acidental, fruto de erros ou defeitos considerados normais dos processos de embalagem, ou provocados pelas razões mais diversas, como extorsão, ganho de dinheiro, publicidade etc.

Em se tratando de segurança alimentar, é importante destacar os aspectos da informação a respeito das condições de armazenamento, conservação e uso fatores que contribuem para a utilização do produto no prazo e em condições onde a sua qualidade e segurança é, em princípio, garantida. Também é importante a informação incluída na embalagem para rastreabilidade do produto (como o número 
do lote) que permite, no caso de ocorrência de problemas - com matérias-primas, processo ou outros -, localizar, limitar e recolher produto defeituoso ou que possa colocar em risco a segurança do consumidor.

O consumidor quer algo fácil de ser visualizado, atraente e que o convença de que será útil em casa. Nesse sentido, não se pode ver a embalagem separada do produto. Uma embalagem de qualidade chega a ser tão importante quanto o que está dentro dela, sendo responsável por $60 \%$ da qualidade do produto (PRIA, 2000).

Portanto, se embalar de forma correta os produtos é função essencial da empresa, possibilitar o bom desembalar também deve ser considerado juntamente com o design, rotulagem, material, confecção final e disposição do produto no ponto de venda. Assim, uma experiência desagradável no ato de desembalar pode, além de afetar a eficácia do produto, seja pela dificuldade de manuseio ou por alguma deficiência não aparente, ainda restringir a eficiência dos objetivos de marketing aplicados às embalagens.

\section{CONSIDERAÇÕES FINAIS}

A embalagem dos produtos é capaz de comunicar uma mesma linguagem onde quer que ela vá. A importância da embalagem cresce como acessório de venda do produto, agregando-Ihe valor, ou por meio de diferenciais que o diferenciem dos concorrentes. Todos os aspectos gráficos da embalagem e as informações transmitidas assumem um importante papel no reconhecimento de uma marca, ao criar, em sua totalidade, uma percepção diferenciada do produto junto ao consumidor. A embalagem não pode ser vista somente como um item a mais na composição do produto, ela é, na realidade, o último atalho entre o produto que está acondicionando e os olhos do consumidor. Uma vez que a embalagem estimula e provoca a compra, ela também abre o que de mais importante há para o produto: o mercado.

A atratividade da embalagem é a relação mais forte com a marca, na medida em que agrega valor a esta e, muitas vezes, torna-se fundamental na decisão de compra. Assim, o design assume grande importância, e as considerações estéticas, ao que se refere à visão (cor, forma, tipografia), audição (altura, tom e ritmo), toque (material e textura), paladar e olfato, assumem uma grande relevância 
comunicacional. Informar o conteúdo, enfatizar seus diferenciais competitivos e indicar com clareza para quem o produto foi criado são os itens de grande importância.

A embalagem apresenta-se como elemento no processo de decisão compra, sendo a principal mídia do produto. Seu design precisa interagir diretamente nesse processo, proporcionando impacto visual, emocional (criar vínculos mais profundos), racional (motivar estímulos para fazer o consumidor migrar da observação à ação de compra) e fidelização (manter a marca sempre atraente para conquistar o consumidor).

Quanto ao instrumento de pesquisa, salienta-se que demais melhorias devem ser feitas para melhorar a sua validade e confiabilidade para, assim, gerar melhores resultados. No momento não se procurou obter a representação perfeita do instrumento e sim a representação válida para alcançar o objetivo da pesquisa.

A embalagem, nos dias atuais, agrega valor ao produto. Se o comunicador final ou intermediário enxergar a embalagem como a própria imagem do produto, ele agregará valor à marca e, por conseguinte, à imagem positiva, e passará a pagar o preço que a empresa achar justo para aquele determinado produto.

Como possibilidade de trabalhos futuros, sugere-se que sejam realizados estudos com produtos específicos, nos quais a embalagem apresente forte influência. Ou, ainda, com produtos para os quais a embalagem não é considerada como fundamental, para observar se os níveis de resposta por tipo de envolvimento se mantêm consistentemente.

\section{REFERÊNCIAS}

ASSOCIAÇÃO BRASILEIRA DE EMBALAGEM (ABRE). Dados de mercado, 2008. Disponível em: <http://www.abre.org.br>. Acesso em: 03 abr. 2009.

. Dados de mercado, 2009. Disponível em: <http://www.abre.org.br>. Acesso em: 03 abr. 2009.

Dados de mercado, 2010. Disponível em: <http://www.abre.org.br>. Acesso em: 25 fev. 2011.

Dados de mercado, 2011. Disponível em: <http://www.abre.org.br>. Acesso em: 17 abr. 2011.

BARTHOLME, R. H.; MELEWAR, T. C. Remodelling the corporate visual identity 
construct: a reference to the sensory and auditory dimension. Corporate Communications: An International Journal, v. 16, n. 1, p. 53-64, 2011.

BAXTER, M. Projeto de produto: guia prático para o desenvolvimento de novos produtos. São Paulo: Editora Edgard Blucher Ltda, 1998.

BLACKWELL, R. D.; ENGEL, J. F.; MINIARD, P. F. Comportamento do consumidor. São Paulo: Thomson Learning, 2005.

BORIN, N.; CERF, D. C. Consumer effects of environmental impact in product labeling. Journal of Consumer Marketing, v. 28, n. 1, p. 76-86, 2011.

BUELOW, S.; LEWIS, H.; SONNEVELD, K. The role of labels in directing consumer packaging waste. Management of Environmental Quality: An International Journal, v. 21, n. 2, p. 198-213, 2010.

CHINEM, M. J.; FLÓRIO, M. A sinergia do design de embalagem na comunicação publicitária. Revista UNIREVISTA, v. 1, n. 3, p. 1-11, jul. 2006.

EMBALAGEM \& CIA. Celulósicas: um segmento em expansão. Revista Embalagem \& Cia, p. 24-29, set. 2001.

FARIA, M. A.; SOUSA, C. V. A influência da embalagem no composto de marketing. In: CONGRESSO NACIONAL DE EXCELÊNCIA EM GESTÃO, 4., 2008, Niterói. Anais.... Rio de Janeiro: UFF, 2008. p. 1-18.

GARCÍA-ARCA, J.; PRADO, J. C. P. Packaging design model from supply chain approach. Supply Chain Management: An International Journal, v. 13, n. 5, p. 375-380, 2008.

GOFMAN, A.; MOSKOWITZ, H. R. Accelerating structured consumer-driven package design. Journal of Consumer Marketing, v. 27, n. 2, p. 157-168, 2010.

GOLLETY, M.; GUICHARD, N. The dilemma of flavor and color in the choice of packaging by children. Young Consumers, v. 12, n. 1, p. 82-90, 2011.

GONÇALVES, A. A.; PASSOS, M. G.; BIEDRZYCKI, A. Percepção do consumidor com relação à embalagem de alimentos: tendências. Estudos Tecnológicos, v. 1, n. 3, p. 271-283, 2008.

GUSTAFSSON, K. et al. Retailing Logistics and Fresh Food Packaging: Managing Change in the Supply Chain. London: Kogan Page, 2006.

HAIR, J. et al. Análise multivariada de dados. 5. ed. Porto Alegre: Bookman, 2006.

JAHRE, M.; HATTELAND, C. J. Packages and physical distribution: implications for integration and standardization. International Journal of Physical Distribution \& Logistics Management, v. 34, n. 2, p. 123-139, 2004. 
KAUPPINEN-RÄISÄNEN, H.; LUOMALA, H. T. Exploring consumers' productspecific colour meanings. Qualitative Market Research: An International Journal, v. 13 , n. 3, p. 287-308, 2010.

KOTLER, Philip. Administração de marketing. 5. ed. São Paulo: Atlas, 1998.

KUMAR, S.; HONG, Q. S.; HAGGERTY, L. N. A global supplier selection process for food packaging. Journal of Manufacturing Technology Management, v. 22, n. 2, p. 241-260, 2011.

LEE, S. G.; LYE, S. W. Design for manual packaging. International Journal of Physical Distribution \& Logistics Management, v. 33, n. 2, p. 163-189, 2003.

LÖFGREN, M.; WITELL, K. Kano's theory of attractive quality and packaging. Quality Management Journal, v. 12, n. 3, p. 7-20, 2004.

LÖFGREN, M. The leader of the pack: a service perspective on packaging and customer satisfaction. Dissertation (Business studies) - Karlstad University Studies, Faculty of Economic Sciences, Communication and IT, Sweden, 2006.

MARKOVINA, J. et al. Young consumers' perception of functional foods in Croatia. British Food Journal, v. 113, n. 1, p. 7-16, 2011.

MASON, H, ROBINSON, L. The information-related behaviour of emerging artists and designers: inspiration and guidance for new practitioners. Journal of

Documentation, v. 67, n. 1, p. 159-180, 2011.

MOREIRA, J. C. T. et al. Gerencia de produto. 1. ed. São Paulo: Saraiva, 2004. v. 1.

NEVES, M. F.; CASTRO, L. T. Marketing e estratégia em agronegócios e alimentos. 1. ed. São Paulo: Atlas, 2007.

OGBA, I., JOHNSON, R. How packaging affects the product preferences of children and the buyer behaviour of their parents in the food industry. Young Consumers, v. 11, n. 1, p. 77-89, 2010.

OZIMEK, I.; ZAKOWSKA-BIEMANS, S. Determinants of Polish consumers' food choices and their implication for the national food industry. British Food Journal, v. 113, n. 1, p. 138-154, 2011.

PACKFORSK, THE FOUNDATION. Packaging and the Environment. Sweden: Packforsk, 2001.

PELEGRINI, A. V.; KISTMANN, V. B. Embalagens para produtos de consumo: o design considerando aspectos de projeto, interfaces e gestão. In: CONGRESSO BRASILEIRO DE GESTÃO E DESENVOLVIMENTO DE PRODUTOS, 4., 2003, Gramado. Anais... Gramado: UFRGS, 2003. 
PENSZ, E.; HOGG, M. K. The role of mixed emotions in consumer behavior: investigating ambivalence in consumers' experiences of approach-avoidance conflicts in online and offline settings. European Journal of Marketing, v. 45, n. 1/2, p. 104-132, 2011.

PEREZ, C. Signos da marca. São Paulo: Pioneira Thomson Learning, 2004.

PEREZ, C. Embalagens ativas prolongam tempo de vida útil de alimentos: aditivos interagem com os produtos para manter a qualidade e aumentar o tempo de prateleira. CENÁRIO, 21., 2008. Disponível em:

<http://www.cpopular.com.br/cenarioxxi/conteudo/mostranoticia.asp?noticia $=1595735 \&$ area $=2259 \&$ authent $=13 F 437$ BAFFF8BB143F3071F833BCDF $>$. Acesso em: 05 jun. 2009.

POÇAS, M. F. F.; MOREIRA, R. Segurança alimentar e embalagem. Porto: ESB/UCP, 2003.

PRENDERGAST, G.; PITT, L. Packaging, marketing, logistics and the environment: are there trade-offs? International Journal of Physical Distribution \& Logistics Management, v. 26, n. 6, p. 60-72, 1996.

PRESAS, P. P.; PRESAS, J. F. Embalagem - o meio e a mensagem: notas para um debate. In: CONGRESSO BRASILEIRO DE CIÊNCIAS DA COMUNICAÇÃO, 30. 2007, Santos. Anais... Santos: INTERCOM, 2007.

PRIA, M. D. As tendências da indústria de embalagens. Brasil Alimentos, n. 4, set./out., 2000. Disponível em: <www.signuseditora.com.br/ba/pdf/04/04\%20\%20Embalagens.pdf>. Acesso em: 12 jan. 2009.

RETTIE, R.; BREWER, C. The verbal and visual components of package design. Journal of Product \& Brand Management, v. 9, n. 1, p. 56-70, 2000.

ROCCHI, B.; STEFANI, G. Consumers' perception of wine packaging: a case study. International Journal of Wine Marketing, v. 18, n. 1, p. 33-44, 2005.

RUNDH, B. The multi-faceted dimension of packaging: marketing logistic or marketing tool? British Food Journal, v. 107, n. 9, p. 670-684, 2005.

RUNDH, B. Packaging design: creating competitive advantage with product packaging. British Food Journal, v. 111, n. 9, p. 988-1002, 2009.

SARANTÓPOULOS, C. I. G. L. et al. Embalagens plásticas flexíveis: principais polímeros e avaliação de propriedades. Campinas: ITAL/CETEA, 2002.

SCATOLIM, R. L. A importância do rótulo na comunicação visual da embalagem: uma análise sinestésica do produto, 2006. Disponível em: <http://www.bocc.ubi.pt>. Acesso em: 12 jan. 2009.

SHETH, J. N.; MITTAL, B.; NEWMAN, I. B. Comportamento do cliente: indo além 
do comportamento do consumidor. São Paulo: Atlas, 2001.

SIEGRIST, M.; STAMPLI N.; KASTENHOLZ, H. Consumers' willingness to buy functional foods. The influence of carrier, benefit and trust. Appetite, v. 51, n. 3, p. 526-529, 2008.

SILAYOI, P.; SPEECE, M. Packaging and purchase decisions: an exploratory study on the impact of involvement level and time pressure. British Food Journal, v. 106, n. 8, p. 607-628, 2004.

SILAYOI, P.; SPEECE, M. The importance of packaging attributes: a conjoint analysis approach. European Journal of Marketing, v. 41, n. 11/12, p. 1495-1517, 2007.

SINGH, P.; GOYAL, G. K. Modified atmosphere packaging and storage on sensory characteristics of ready-to-bake pizza. Nutrition \& Food Science, v. 40, n. 3, p. 299304, 2010.

SINGH, P.; WANI, A. A. Active packaging of food products: recent trends. Nutrition \& Food Science, v. 41, n. 4, p. 1-14, 2011.

UNDERWOOD, R. L.; KLEIN, N. M.; BURKE, R. R. Packaging communication: attentional effects of product imagery. Journal of Product \& Brand Management, v. 10, n. 7, p. 403-422, 2001.

URALA, N.; LÄHTEENMÄKI, L. Attitudes behind consumers' willingness to use functional foods. Food Quality and Preference, v. 15, n. 7-8, p. 793-803, 2004.

VENTER, K. et al. Consumers' perceptions of food packaging: an exploratory investigation in Potchefstroom, South Africa. International Journal of Consumer Studies, v. 34, n. 6, p. 1-9, 2010.

VERNUCCIO, M.; COZZOLINO, A.; MICHELINI, L. An exploratory study of marketing, logistics, and ethics in packaging innovation. European Journal of Innovation Management, v. 13, n. 3, p. 333-354, 2010.

ZAYER, L. T.; NEIER, S. An exploration of men's brand relationships. Qualitative Market Research: An International Journal, v. 14, n. 1, p. 83-104, 2011.

WELLS, L. E.; FARLEY, H.; ARMSTRONG, G. A. The importance of packaging design for own-label food brands. International Journal of Retail \& Distribution Management, v. 35, n. 9, p. 677-690, 2007.

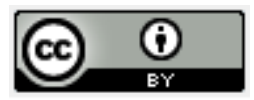

Artigo recebido em 18/03/2011 e aceito para publicação em 20/09/2011. 